\title{
Letter to Editor: A Report on the First Meeting on the Role of the Nurses Working in the Intensive Care Units in Emergencies and Disasters in Iran
}

\author{
Fatemeh Bahramnezhad $^{1}$ (D, Zahra Abbasi Dolatabadi ${ }^{1 *}$ (D)
}

1. Department of Critical Care Nursing, Faculty of Nursing and Midwifery, Tehran University of Medical Sciences, Tehran, Iran.

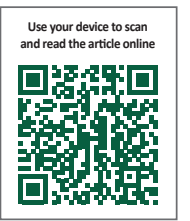

Citation: Bahramnezhad F, Abbasi Dolatabadi Z. A Report on the First Meeting on the Role of the Nurses Working in the Intensive Care Units in Emergencies and Disasters in Iran. Health in Emergencies and Disasters Quarterly. 2019; 5(1):1-4. http://dx.doi. org/10.32598/hdq.5.1.179.1

dei $h$ http://dx.doi.org/10.32598/hdq.5.1.179.1

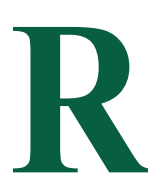

egarding the consequences of emergencies and disasters for human beings, the health system, especially hospitals is the first involved places. Continuity of the service delivery by hospitals after emergencies and disasters is one of the most important issues that should be considered by all people and authorities. Hospitals are needed to promote their preparedness prior to the occurrence of emergencies and disasters [1, 2]. In this regard, the Joint Commission for Accreditation of Healthcare Organization emphasizes the safety and vulnerability assessment of the healthcare organizations in three structural, nonstructural, and managerial domains [3, 4].

In each hospital, disaster preparedness in different units consistent with the services they provide is of great importance. Over the last 70 years, the development of modern Intensive Care Units (ICUs) with high costs has increased the survival rate of patients with life-threatening conditions [5]. ICU is a specialized unit of a hospital that provides care for patients at high risks or critically-ill patients. Patients in these units receive services supervised by the experienced and trained healthcare team. According to the type of hospitalized patients, equipment, and intensive care level these units are more vulnerable in emergencies and disasters.
Before emergencies and disasters, ICUs should be prepared for potential events, because in such situations, the need for special and vital healthcare services also intensively increases. Accordingly, nowadays, ICUs should be widely considered in planning for hospital emergency preparedness [6].

Most of the ICUs have a normal functional capacity, which is at a very low level at the time of emergencies and disasters due to the limitations, such as adequate space, method of patient transfer, triage of patients, experienced medical staff, and no appropriate medical equipment and structural and non-structural safety levels. As a result, while planning for preparedness against emergencies and disasters, ICUs should be evaluated regarding the structural and non-structural preparedness and also ICT management. Planners are informed that despite preparedness, they are unable to respond to the emergencies and disasters completely, however, accurate planning by ICUs enables the personnel to efficiently react against these events. The results of previous relevant studies shows that inappropriate design of the units, equipment, and also lack of experienced healthcare team are main causes for inadequate preparedness of these units in disasters $[6,7]$.

A limited number of studies have conducted on the assessment of safety and preparedness of ICUs. In emergencies and disasters, lack of enough space and equipment in ICUs are two fundamental concerns. In emergencies, all

* Corresponding Author:

Zahra Abbasi Dolatabadi, PhD.

Address: Department of Critical Care Nursing, Faculty of Nursing and Midwifery, Tehran University of Medical Sciences, Tehran, Iran.

E-mail: zahra_abasi2000@yahoo.com 
departments of the hospital should act as intensive units, which is accessible by appropriate planning by authorities before emergencies and disasters.

For this planning, potential vulnerabilities, potential capacity for hospitalized patients and transferring them to other centers, and human resource management should be assessed [7]. Despite of designing equipment for hospital safety assessment, as well as efforts for the preparedness of healthcare team in emergencies and disasters since 2008 [8], no educational package or instrument was found to evaluate the safety and preparedness of the intensive care departments, such as ICU and CCU. However, fundamental measures have taken regarding preparedness in dialysis and neonatal intensive care units.

Iran compared with other countries is a disaster-prone country. Regarding the Sendai priorities and also disaster risk management at different levels of the society, a oneday meeting entitled "the role of nurses in emergency care units in disasters and emergencies" was held at the international Pastor day (May 12, 2018) in the Faculty of Nursing and Midwifery, Tehran University of Medical Sciences, Iran. The nurses working in ICUs and healthcare experts in emergencies and disasters cooperated to conduct the meeting.

In this seminar and after presenting an introduction about the preparedness level of Iran in emergencies and disasters and the role of hospitals and ICUs in disasters, nurses stated their experiences about different disasters, such as the Bam and Kermanshah earthquakes and fire in the ICUs and also pointed to the disaster management achieved by their organizations and these activities were discussed.

The most important experiences of nurses participated in this meeting were as follows: inappropriate equipment management, no skilled personnel, inappropriate management and leadership, lack of awareness about triage of patients, no adequate financial support, lack of fire management, high number of requests to provide equipment from these units, unsafety of the units, devices and equipment falling down, no power and water, excessive presence of personnel in the unit and lack of its appropriate management, lack of possibility to replace skilled personnel when needed, lack of attention to the comfort of personnel regarding safety of their family members, and the lack of training courses for families about providing care at home during emergencies and disasters.

In this meeting, some suggestions, such as holding workshops on the ICUs, establishment of an exclusive research center in this field, publishing a specialized journal, con- ducting more relevant studies, using the experiences of those involved in such situations, and designing an instrument to check the safety of the ICUs were proposed. Also, one of the most important suggestions in this meeting was holding international seminars and meetings to exchange experiences between different countries about the preparedness of ICUs in emergencies and disasters.

\section{Ethical Considerations}

\section{Compliance with ethical guidelines}

All ethical principles were considered in this article.

\section{Funding}

This research did not receive any specific grant from funding agencies in the public, commercial, or not-forprofit sectors.

\section{Authors' contributions}

All authors contributed in preparing this article.

\section{Conflict of interest}

The authors declared no conflict of interest.

\section{References}

[1] Corcoran SP, Niven AS, Reese JM. Critical care management of major disasters: A practical guide to disaster preparation in the intensive care unit. Journal of Intensive Care Medicine. 2012; 27(1):3-10. [DOI:10.1177/0885066610393639] [PMID]

[2] Hendrickx C, D'Hoker S, Michiels G, Sabbe MB. Principles of hospital disaster management: An integrated and multidisciplinary approach. B-ENT. 2016; 12(Suppl. 26/2):139-48. [PMID]

[3] Daugherty EL, Rubinson L. Preparing your intensive care unit to respond in crisis: Considerations for critical care clinicians. Critical Care Medicine. 2011; 39(11):2534-9. [DOI:10.1097/CCM.0b013e3182326440] [PMID]

[4] Joint Commission on Accreditation of Healthcare Organizations. Health care at the crossroads: Strategies for creating and sustaining community-wide emergency preparedness systems. Washington, DC: The Library of Congress; 2003. https://www.loc.gov/item/2004296050/

[5] Weil MH, Tang W. From intensive care to critical care medicine: A historical perspective. American Journal of Respiratory and Critical Care Medicine. 2011; 183(11):1451-3. [DOI:10.1164/rccm.201008-1341OE] [PMID] 
[6] Echevarría-Zuno S, Cruz-Vega F, Elizondo-Argueta S, Martínez-Valdés E, Franco-Bey R, Méndez-Sánchez LM. Medical care during emergency and disaster response in Critical Care Units in the Mexican Social Safty Institute: Triage and evacuation. Cirugía y Cirujanos. 2013; 81:228-37. https:// pdfs.semanticscholar.org/5eb2/31487692508712b1dddf2f9d fdea0c564e76.pdf

[7] Hotchkin DL, Rubinson L. Modified critical care and treatment space considerations for mass casualty critical illness and injury. Respiratory Care. 2008; 53(1):67-77. [PMID]

[8] World Health Organization, Pan American Health Organization. Hospital safety index: Guide for evaluators [Internet]. 2015 [Updated 2015]. Available from: https://apps.who.int/ iris/handle/10665/258966 
This Page Intentionally Left Blank 